\title{
Algorithm based improvement of clinical quality
}

\author{
Stephen C Schoenbaum, Lawrence K Gottlieb
}

Ambulatory medical practice has traditionally taken place behind closed office doors. In recent years there has been a shift of important clinical decision making from the hospital setting to the physician's office, and ambulatory practices have been organised into managed entities (for example, health maintenance organisations and large group practices). Concomitantly, there has been an increasing interest in managing the practice that occurs behind the closed office door without violating the confidentiality of the physician-patient relationship. Problems relating to widespread variation in practices and practice styles have begun to surface, and the issue is not whether, but how best, to manage the variation. One approach, which is increasingly discussed, is to develop guidelines for practice. Though developing and disseminating guidelines undoubtedly will be increasingly important in managing clinical practices, guidelines are just the initial component of a cyclical process for improving clinical performance.

In this article we illustrate some of the clinical management issues that managers face; provide a general framework for dealing with those problems, which includes developing and implementing practice guidelines; give a specific example of a clinical quality improvement project in our own organisation; and make some general points about the opportunities and difficulties of this approach.

\section{Clinical management issues}

Consider the treatment of a common situation such as prescribing oral contraceptives. About 20 different brand names are marketed in the United States, each with various formulations and dosages. One advantage of an organisation of managed care is that it should be able to purchase pharmaceuticals in high volume at a favourable price and pass the savings to its patients. How can the organisation influence the physician to write for a limited number of products? How does it obtain the desired behaviour without interfering with the "best judgment" of the physician?

Consider a different problem. Two patients, who are friends, have the same clinical condition but are treated differently by two physicians who work for the same health care organisation. One patient has a bad outcome. The friends compare notes and discover the difference in the way they were handled and in their outcomes. The one with the bad outcome asks the management of the health care organisation to explain the difference. Though the difference really may not be explainable, the management often states that there are many different "acceptable" ways to handle the same problem. Yet, if care is managed, shouldn't there have been careful consideration of the benefits, risks, and costs of treatment by the physicians in the organisation? Shouldn't those physicians have concluded either that there is an optimal approach or that several approaches are equally acceptable? Should the organisation tolerate unexplained variation in care when it is potentially liable for the poor outcomes?

Schoenbaum, Harvard Community Health Plan, 10 Brookline Place West, Brookline, MA 02146 , United States.

\section{Process of clinical quality improvement}

Such considerations in 1985 led Harvard Community Health Plan, a large health maintenance organisation

\section{The clinical quality improvement process}

Definition and organisation of project

List and prioritise problems

Define project and team

Development of guidelines

Identify relevant individuals and assess their needs

Consider scientific evidence

Consider clinical experience

Consider outcomes and preferences

Develop consensus guidelines

\section{Problem prevention and implementation}

Consider potential problems and causes

Develop support systems for prevention

Design measurement system

Implement guideline and systems supports

\section{Measurement and evaluation}

Measure performance: process and outcomes

Monitor systems

in the Boston area of Massachusetts, to initiate an activity for developing and implementing clinical standards or guidelines. ${ }^{1}$ Although guidelines may be useful for the retrospective assessment of care, we wanted to develop tools and programmes to assist or support clinicians in delivering appropriate care. In this context we consider a guideline to be just one part of a support system for managing clinical care. Our guidelines have usually taken the form of algorithms, as the process of care is often best described by a linked series of "if. . . then" statements. The basic elements of the clinical quality improvement process may be broken down into four distinct phases (box). Once a particular clinical process is selected for quality improvement a team of clinicians and managers is assembled and the focus of the project is clarified. The team then proceeds to analyse the problem, identify the relevant staff involved in the care process, and develop a consensus guideline based on the available scientific evidence and the group's clinical experience. Once the guideline is completed the group must consider potential barriers to the faithful execution of the care plans specified by the guideline and design a strategy to overcome those barriers. Potential problem areas may be related to the knowledge and skills of the clinician, the capabilities of the delivery system, and the overall practice environment. Preventive measures may include publication and distribution of the guideline, focused education programmes, automated and manual decision support systems (including clinical reminder systems), and administrative mechanisms. Once the preventive measures are specified, key quality indicators are identified and a measurement plan is designed. After the new clinical guidelines and systems supports are implemented performance is measured and another round of the quality improvement cycle is initiated as appropriate.
Clinical quality improvement in screening for

Cervical cancer screening by the use of the Papanicolaou smear is a common and important procedure in cervical cancer 
ambulatory care. When considering the quality of care for female patients who undergo cervical cytological screening attention usually has been directed to the quality of the laboratory reading the smear. The overall process, however, consists of multiple steps, each of which must be carried out properly to assure high quality care. The steps include obtaining specimens at the appropriate intervals from the entire population at risk, obtaining specimens that are most suitable for reading, handling them so that they get to the laboratory promptly in good condition, reading them accurately and expeditiously, notifying the clinician of the results appropriately, notifying the patient, and performing suitable follow up care for women with an abnormal result.

We have tried to assess and, if necessary, modify each step in this process: the department of quality of care measurement at the Harvard Community Health Plan performs surveys of screening practices among our members by reviewing medical records. In 1989, for example, in Harvard Community Health Plan's health centers division, an organisation which delivers care to over 300000 members at 12 sites, $92 \%$ of new female members who had an initial health assessment were recorded to have had a pelvic examination and smear, and $76 \%$ of a random sample of women who had been members for at least one year had had a Papanicolaou smear recorded in the previous two years. This practice is supported by an automated reminder system that, for every routine primary care encounter, prints out an age-sex specific listing of recommended screening practices. $^{2}$ There is possible room for improvement at this step as we still may be missing women who have not had a visit and may be screening others more often than necessary.

The Harvard Community Health Plan's central

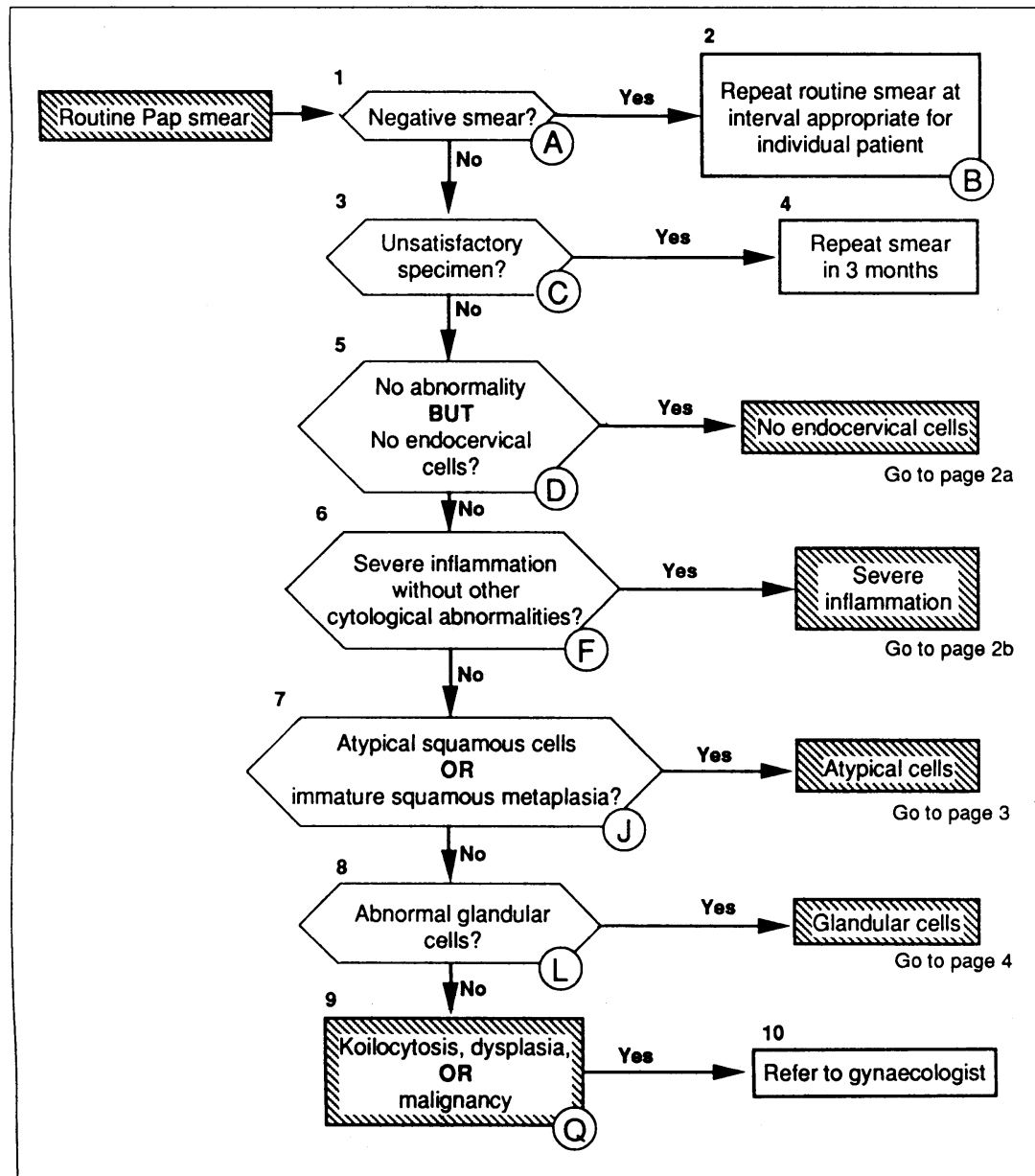

FIG 1-Evaluation and management of abnormal Papanicolaou (Pap) smear by primary care providers (March 1989)
Algorithm summary of evaluation and management of abnormal Papanicolaou (Pap) smear by primary care providers (March 1989)

\begin{tabular}{|c|c|}
\hline Papanicolaou result & Recommended follow up \\
\hline Negative & $\begin{array}{l}\text { Repeat routine smear at interval } \\
\text { appropriate for individual patient (Box } 1 \text {, } \\
\text { annotations } A \text { and } B \text { ) }\end{array}$ \\
\hline Unsatisfactory & $\begin{array}{l}\text { Repeat smear in } 3 \text { months. (Box } 3 \text {, } \\
\text { annotation C) }\end{array}$ \\
\hline $\begin{array}{l}\text { No abnormality, BUT no } \\
\text { endocervical cells }\end{array}$ & $\begin{array}{l}\text { Repeat smear in } 3 \text { months or one year } \\
\text { depending on results of previous smears } \\
\text { (Box } 5 \text {, annotations D and } E \text { ) }\end{array}$ \\
\hline $\begin{array}{l}\text { Severe inflammation without } \\
\text { other cytological } \\
\text { abnormalities }\end{array}$ & $\begin{array}{l}\text { Consider treatment for infectious agents or } \\
\text { atrophic changes as indicated (Box } 6 \text {, } \\
\text { annotations F-I) }\end{array}$ \\
\hline $\begin{array}{l}\text { Atypical squamous cells OR } \\
\text { immature squamous } \\
\text { metaplasia }\end{array}$ & $\begin{array}{l}\text { Treat any identified infections or atrophic } \\
\text { changes. Repeat smear every } 3 \text { months, } \\
\text { twice. Refer to gynaecologist if either } \\
\text { repeat smear is abnormal (Box } 7 \\
\text { annotations } J \text { and } K \text { ) }\end{array}$ \\
\hline Endometrial cells & $\begin{array}{l}\text { If patient is postmenopausal refer to } \\
\text { gynaecologist, if premenopausal repeat } \\
\text { smear at mid-cycle and refer if } \\
\text { endometrial cells persist. (Boxes } 8 \text { and } \\
29 \text {, annotations } M-O \text { ) }\end{array}$ \\
\hline Atypical endocervical cells & $\begin{array}{l}\text { Evaluate and treat for possible infectious } \\
\text { aetiologies. Repeat smear in } 3 \text { months. } \\
\text { Refer to gynaecologist if atypical } \\
\text { endocervical cells persist (Boxes } 8 \text { and 34, } \\
\text { annotation P) }\end{array}$ \\
\hline $\begin{array}{l}\text { Koilocytosis, dysplasia, or } \\
\text { malignancy }\end{array}$ & $\begin{array}{l}\text { Refer to gynaecologist (Box } 9, \\
\text { annotation Q) }\end{array}$ \\
\hline
\end{tabular}

cytology laboratory is processing almost 100000 smears annually. The laboratory is accredited and has a strong quality control programme. Though there has been considerable concern in recent years about the accuracy of readings in many cytology laboratories, our concerns were primarily directed to the processes of acquiring and following up smears. Endocervical elements (endocervical glandular cells and squamous metaplastic cells) were present in only $37-45 \%$ of the smears, and we found that there was substantial variation in the techniques by which specimens were being obtained. Though a trial of training in optimal technique improved the rate of endocervical elements present to $70 \%$, a working group of our internists and gynaecologists convened to develop guidelines for cervical cancer screening practices and follow up ultimately recommended use of endocervical brushes to improve the yield of endocervical elements even more and avoid the need for many repeat smears. Implementing this technique by in service education and including the brush in the equipment for pelvic examinations increased the rate of recovery of endocervical elements to $87-89 \%$ with an appreciable decrease in variation among clinicians.

The working group developed algorithms for evaluating and managing abnormal smears by primary care providers (fig 1) and by gynaecologists. Figure 1 shows the overall algorithm, and figure 2 shows the portion of the algorithm specifying follow up of patients with abnormal glandular cells.

The practical question is how to help physicians do the follow up steps in the table and do them uniformly. We chose to support the implementation of this algorithm by programming our laboratory system with a set of prompts. Accordingly, when an abnormal cervical smear test result is reported from the laboratory to the physician the report contains a statement of the follow up recommended by the algorithm (a prompt). This process dovetails with a reminder system, which in turn is linked to our COSTAR based automated medical record system. ${ }^{2}$ The record system periodically searches the records of patients with abnormal smear test results to determine if the first follow up step has occurred in the appropriate time interval. If not the physician is notified. Reminders such as these circumvent problems which arise because the original laboratory result was lost or ignored by the clinician or patient. Data from our department of quality of care measurement indicate that only two thirds of patients 
with abnormalities on smear testing have had an appropriate follow up recorded within the first three months; by six months, however, $99 \%$ have had an appropriate follow up. Given the volume of activity, the remaining $1 \%$ represents almost 50 patients a year with an abnormal smear who have not had appropriate follow up. Accordingly, we instituted a manual reminder system for the residual $1 \%$ and now know that we have notified or treated all patients with abnormal smear test results.

\section{General comments}

The example of cervical cancer screening gives some notion of the complexity of managing medical care, even for ostensibly simple and common issues. Is it worth the effort to go through the process of developing and implementing algorithm based or guideline based approaches to care? In general, we believe that it is, for several reasons.

Specifying the overall process of care allows logical assessment and improvement of its components. It draws attention to opportunities to improve quality that tend otherwise to be overlooked - that is, improving screening and follow up performance, not just focusing on technical aspects of preparing and reading smears in the laboratory.

The development of algorithms or guidelines by

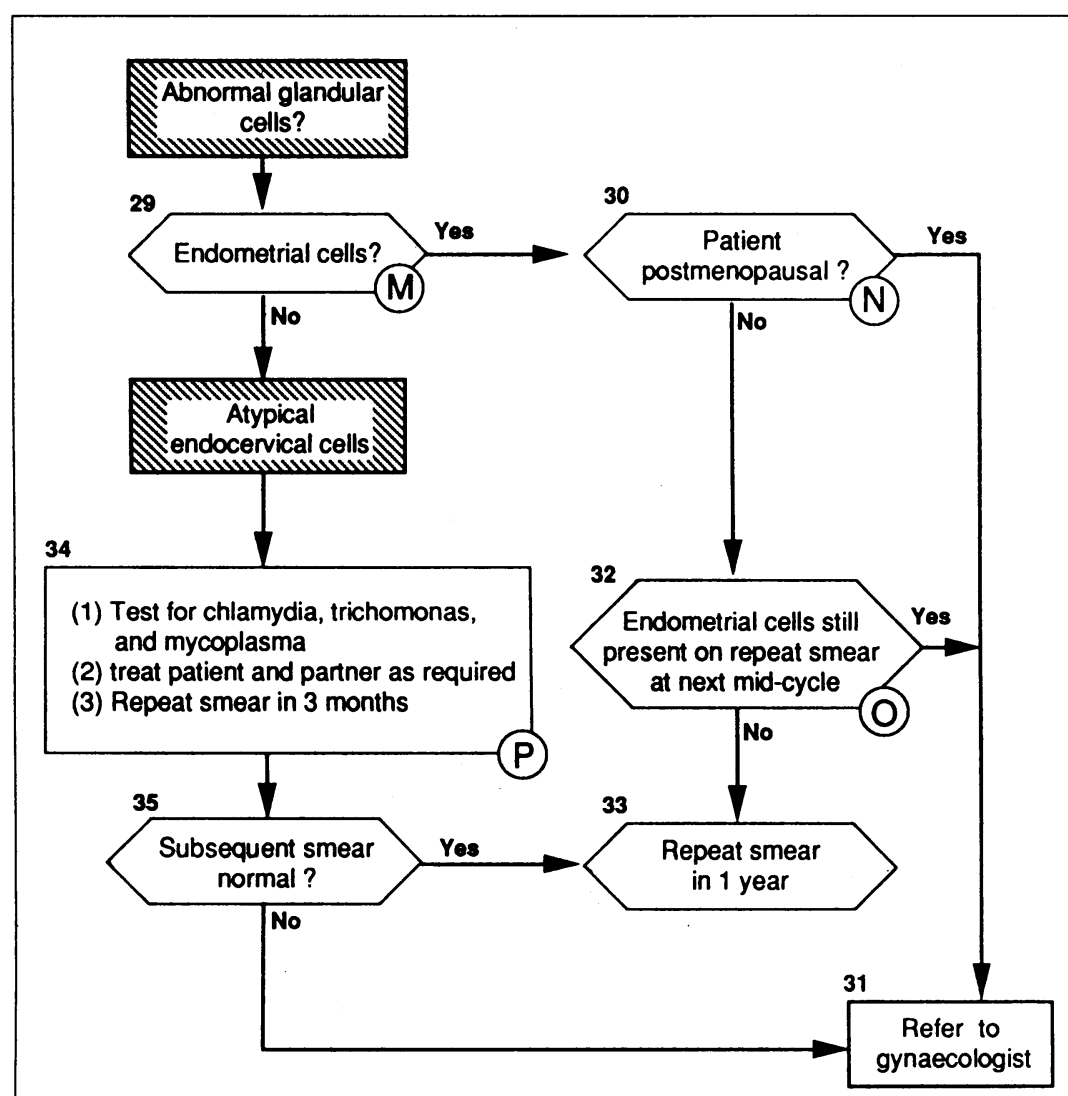

FIG 2-Management for abnormal glandular cells clinicians has educational importance within health care systems. Much knowledge of ambulatory practice has not been shared. When the sharing occurs better ideas arise. Additionally, group work on developing or modifying a guideline leads to its local ratification, an important first step in its implementation.

Developing the algorithm itself does not necessarily ensure improved performance. Nevertheless, the nature of the support systems and measures necessary to improve and monitor performance become apparent . Systems and technologies-for example, use of endocervical brushes-may improve care directly. Measurement not only indicates the success of the intervention but may also be an intervention itself. It provides important feedback to physicians, and feedback is itself a way of improving performance.

Specification of process decreases variation. It leads to standardisation of practices and techniques which can decrease error, waste, rework, and unit cost. When all parties know what to expect it is easier to facilitate the correct procedure and to monitor for error. In our example of cervical cytology screening, standardisation of the use of endocervical brushes permitted the brushes to be included routinely in the equipment for the pelvic examination, which led to greater recovery of endocervical elements and to fewer return visits to collect a better sample. By having achieved agreement on a standard technique we can now develop standardised educational materials to explain to patients the exact nature of the procedure they can expect to undergo; and if a new process improvement is proposed we will be able to compare it with a known standard technique rather than unknown and varying techniques.

On the other hand, the development of guidelines and systems to support them is time consuming, and the expenditures of creating the guidelines and systems are apparent before the savings. It may be necessary to implement automated information systems to facilitate many desirable clinical process improvements, and few models for these exist. In addition, as it is usual to find that performance of recommended clinical processes is less than $100 \%{ }^{3}$ the result of improvements in clinical process may be to offset savings in unit costs of services with increased units of service.

Nevertheless, we have reached a critical juncture in health care and now realise that quality of care is not just a function of using more complex technologies. Evaluating and improving the processes of care is not simple, nor is it a task which in the past was highly rewarded. Now that we have opened ourselves to examination and can see the opportunities for process improvement, we will probably adopt the tools for improvement including development of guidelines or process specification, support systems for implementing improved processes, ongoing measurement of how we are doing, and formal reassessments.

1 Gottlieb LK, Margolis CZ, Schoenbaum SC. Clinical practice guidelines at an HMO: development and implementation in a quality improvement model. Quality Review Bulletin 1990;16:80-6.

2 Schoenbaum SC. implementation of preventive services in an HMO practice. f General Intern Med 1990;5:S123-7.

3 Schoenbaum SC. When is the quality of care good enough? Am $\mathcal{J}$ Public Health 1990;80:403-4.

\section{ONE HUNDRED YEARS AGO}

The planting of eucalyptus trees for the purpose of draining the soil in malarial districts is one which has met with some success. The Trefontane Convent at Rome had become positively uninhabitable, owing to the malaria which attacked - in many instances with fatal results - its inmates. Senator Torelli presented a Bill proposing that the estate annexed to the convent should be planted with eucalyptus as an experiment against malaria. The Bill was passed, and the Trappist monks planted thousands of eucalyptus plants of all species on the estate. But still the malaria raged, and several monks suffered severely. It was, however, remarked that it was only the monks who had their cells looking on the central cloister who fell victims to the malaria. This suggested the idea of planting four eucalyptus trees at the four corners of the cloister. The plants, sheltered from the winds, soon grew to a great height. The immediate result was the complete draining of the soil in the cloister, and the disappearance of malarial fever from the convent. 